\title{
Farmers' Perception towards a Ragi Expert System
}

\author{
C. Bhagavathsingh ${ }^{1}$, K. Mahandrakumar ${ }^{2}$ and N. Sriram ${ }^{3}$
}

\begin{abstract}
A total of 46 statements, that determine the perception of Ragi Expert System, were spread among three main components viz., over all perception, message and technical components. Responses were obtained through structured interview schedule from a sample of 120 respondents who were selected from ten villages of Krishnagiri district of Tamil Nadu. The usefulness, merits and difficulties that they perceived in deriving information and diagnosis symptoms and knowledge gained on remedial measures through expert system were tabulated. Though expert system is powerful to motivate the people, still some more pictorial representation, easy navigation, concurrent information simple and understandable language should be incorporated to reach the farmers on a large scale.
\end{abstract}

Keywords : Expert System; Ragi; Perception, Tamil Nadu

Agricultural production has evolved into a complex business requiring the accumulation and integration of knowledge and information from many diverse sources. In order to remain competitive, the modern farmers often rely on agricultural specialists and advisors to provide information for decision making. Unfortunately, agricultural specialist assistance is not always available when the farmer needs it. In order to alleviate this problem, expert systems were identified as a powerful tool with extensive potential in agriculture. (Prasad and Babu, 2006). Keeping the importance of ICT enabled interventions in agriculture and providing timely expert advice to farmers, Ragi expert system, one among the six expert systems was developed by TNAU (Tamil Nadu Agricultural University) with the help of the ICAR (Indian Council of Agricultural Research) sponsored network project.

The degree of effectiveness of Ragi Expert System can be assessed through respondents' perception. In this context, perception is the process, by which one can be able to see, hear, and understand things. Hence, it is assumed that greater the perception of Ragi Expert System by its users was in terms of satisfaction derived from various components of Ragi Expert System, greater would be the users' exposure and post exposure activities.

A detailed analysis on various components of Ragi Expert System as

1-PG. Scholar, 2-Professor, Department of Agricultural Extension and Rural Sociology,Agricultural College and Research institute, Madurai and 3- Programme coordinator, ICAR-KVK, Salem.

Received : 23-04-2018; Accepted : 17-05-2018 
perceived by the respondents is discussed in this study. Based on the scores obtained by the respondents, they were grouped into three categories viz., highly satisfied, satisfied and not satisfied. A total of 41 sub components, which determine the perception of Ragi Expert System, were spread among three main components viz., over all perception, message component and technical components.

\section{METHODOLOGY}

Krishnagiri district was purposefully selected based on the potentiality of Ragi cultivation. Purposive sampling was followed for selecting 120 respondents. Respondents' perception towards various components of Ragi Expert System was studied. The required data were collected by using wellstructured, pre-tested interview schedule.

\section{FINDINGS AND DISCUSSION}

\section{Overall perception of Ragi Expert System}

The overall perception and componentwise details are presented in Table 1.

Table.1.

Distribution of Respondents according to their Overall perception of Ragi expert system

\begin{tabular}{|c|l|c|c|c|c|c|c|}
\hline \multirow{2}{*}{$\begin{array}{c}\text { SI. } \\
\text { No }\end{array}$} & \multicolumn{1}{|c|}{ Perception statements } & \multicolumn{2}{c|}{ Highly satisfied } & \multicolumn{2}{c|}{ Satisfied } & \multicolumn{2}{c|}{ Not satisfied } \\
\cline { 3 - 8 } & & No. & Percentage & No. & Percentage & No. & Percentage \\
\hline 1 & Adequate information provided & 11 & 9.17 & 64 & 53.33 & 45 & 37.50 \\
\hline 2 & Motivation to learn subject matter & 7 & 5.83 & 35 & 29.17 & 78 & 65.00 \\
\hline 3 & Simple to operate & 9 & 7.50 & 48 & 40.00 & 63 & 52.50 \\
\hline 4 & Interesting to use & 4 & 3.33 & 28 & 23.33 & 70 & 58.34 \\
\hline 5 & Possibility of stored information & 14 & 11.67 & 41 & 34.17 & 65 & 54.17 \\
\hline 6 & Provides complete knowledge & 17 & 14.17 & 62 & 51.67 & 41 & 34.17 \\
\hline 7 & $\begin{array}{l}\text { Motivate to adopt the messages in } \\
\text { farm }\end{array}$ & 9 & 7.50 & 49 & 40.83 & 62 & 51.67 \\
\hline
\end{tabular}

\section{Adequacy of the Information Provided}

Out of 120 respondents above half of the respondents (53.33\%) were satisfied with the adequacy of information provided through Ragi Expert System. But still $37.50 \%$ of the respondents were not satisfied with the adequacy of information provided in expert system. They felt that information regarding input sources and videos for explaining pest and disease management are inadequate.

\section{Motivation to learn Subject matter}

Even after the adequacy of information provided, majority of the respondents (65\%) were not motivated to learn the subject matter through expert system. It might be because the combination of videos and texts were very poor. Detailed information on recent practices 
were not provided in expert system.

\section{Simple to Operate}

About half of the respondents (52.50\%) felt that Expert System is difficult to operate. As the profile characters shows that most of respondents are only mobile users and they were not exposed to various modern gadgets. Moreover, the expert system does not have the prelude of how to use it, might be the reason.

\section{Interesting to Use}

Nearly $60 \%$ of the respondents (58.30\%) reacted that handling of Ragi Expert System was not as interesting. As mentioned earlier, ragi expert system is not simple to operate and it was not provided with more interactive videos are the reason for dissatisfaction, however nearly one fourth of the respondents (23.33\%) felt that it was interesting to use.

\section{Possibility of Stored Information}

Above half of the respondents (54.17\%) were not satisfied towards possibility of stored information. Only one-third (34.17\%) of the respondents were satisfied on possibility of storing the information. This is due to their inadequate knowledge about the computer and its operations, as most of them are new to computer usage.

\section{Provides Complete Knowledge}

Over half (51.67\%) of the respondents were satisfied on completeness of provided information and nearly one third (34.17\%) of respondents were not satisfied with the completeness of information provided. The respondents felt that the crop production aspects alone are being covered. But detailed information on pest and disease management and function of different machinery used for ragi cultivation are lacking.

\section{Motivation to adopt the messages in farm}

Half $(51.67 \%)$ of the respondents were not motivated to adopt the messages in farm. They revealed that the benefits of complex practices are not explained and the details on the source of availability on farm machineries, seeds and traps are not revealed.

The results revealed that the provided messages in the Expert System are inadequate and incomplete to motivate the farmers to enthusiastically involve in operation. Hence efforts should be made to make it more lightly through incorporation of videos and pictures with hassle free navigation.

\section{Message Components}

Perception of various message components on Ragi Expert System as evaluated by the respondents is provided in Table 2.

\section{Understandability of the message}

Above half (67.50\%) of the respondents were satisfied on understandability of the message. This is because the messages were given in regional language and simple sentences were used. However, nearly one fifth $(21.67 \%)$ of the respondents were not satisfied. The names of varieties were given in numerical (Eg. Co 1, PY 1) rather than vernacular names and chemical names for the insecticides made the farmers hard to grasp the message. 


\section{Accuracy of Message}

Nearly sixty percent of respondents (58.33\%) were satisfied with the accuracy of the provided message. Messages are relevant to ragi cultivation practices and inappropriate message have been totally avoided.

\section{Explaining Complex Ideas}

Above two-thirds (65.83\%) of the respondents were not satisfied on explanation of complex ideas. Explanation on installing traps, parasitoid release, nutrient management and functions of machinery have not been explained in detail. Moreover, videos on those aspects are not provided in the Ragi Expert System.

\section{Clarity of Message}

Over two-thirds (68.33\%) of the respondents were satisfied on the clarity of the message provided in ragi expert system. The provided messages are in regional language and simple words are used.

\section{Appropriateness of Message}

About three-fourths $(77.50 \%)$ of the respondents were satisfied on appropriateness of message given in Ragi Expert System. Messages were given with appropriate tittle and cultivation practices are depicted to local conditions.

\section{Reinforcing Key ideas}

Two-thirds (66.67\%) of the respondents were not satisfied on the subcomponent of reinforcing the key ideas. Information on nutrient management and pest management were not available by giving more clear information with videos.

Table.2.

Distribution of Respondents according to their Perception of Message Components

\begin{tabular}{|c|l|c|c|c|c|c|c|}
\hline \multirow{2}{*}{ SI. No } & \multirow{2}{*}{ Perception statements } & \multicolumn{2}{|c|}{$\begin{array}{c}\text { Highly } \\
\text { Satisfied }\end{array}$} & \multicolumn{2}{|c|}{ Satisfied } & \multicolumn{2}{|c|}{ Not satisfied } \\
\cline { 3 - 9 } & & No. & Percent & No. & Percent & No. & Percent \\
\hline 1 & $\begin{array}{l}\text { Understandability of the } \\
\text { message }\end{array}$ & 13 & 10.83 & 81 & 67.5 & 26 & 21.67 \\
\hline 2 & Accuracy of message & 16 & 13.33 & 70 & 58.33 & 34 & 28.33 \\
\hline 3 & Explaining complex idea & 5 & 4.17 & 36 & 30.00 & 79 & 65.83 \\
\hline 4 & Clarity of message & 15 & 12.50 & 82 & 68.33 & 23 & 19.17 \\
\hline 5 & Appropriateness of message & 6 & 5.00 & 93 & 77.50 & 21 & 17.50 \\
\hline 6 & Reinforcing key ideas & 8 & 6.67 & 32 & 26.67 & 80 & 66.67 \\
\hline 7 & $\begin{array}{l}\text { Giving source of information } \\
\text { for inputs }\end{array}$ & 0 & 0.00 & 13 & 10.83 & 107 & 89.17 \\
\hline 8 & $\begin{array}{l}\text { Multidisciplinary nature of the } \\
\text { subject }\end{array}$ & 5 & 4.17 & 51 & 42.50 & 64 & 53.33 \\
\hline
\end{tabular}


Giving Source of Information for Inputs

Nearly $90 \%$ of the respondents ( 89.17 $\%)$ were not satisfied on the information regarding giving source for inputs. Details on inputs like seeds, micro nutrients, bio fertilizers, light trap, pheromone trap and machinery were not provided in the Ragi Expert System.

\section{Multidisciplinary Nature of the Subject}

Just over half $(53.33 \%)$ of the respondents were not satisfied on the multidisciplinary nature of the subject. Information was in text format. Videos and audios regarding field preparation, planting, nutrient management, plant protection and post-harvest practices were not provided.

It is found that message components need more refinement in the aspects of explanation on complex ideas, reinforcing key ideas, source of information on inputs and incorporating multidisciplinary expert judgment on subjects.
The study has revealed that, majority of the respondents were just satisfied on text used in Ragi Expert System. Improvements in the colour combination for the text would result in higher satisfaction among farmers. The results clearly depict that, video clippings available in the Ragi Expert System were inadequate to meet the need of the farmers and messages in videos were understandable to the farmers. Rectification of the errors in the video clippings of the ragi expert system would help to reach many farmers. Most of the respondents were just satisfied on many components of Ragi Expert System. This indicates that there is lot of scope for improving the Ragi Expert System to reach the farmers at grass root level.

\section{REFERENCES}

Anandaraja, N. (2002). Developing Farmer Friendly Interactive Multimedia Compact Disc and Testing its Effectiveness in Transfer of Farm Technology. Unpublished Ph.D. Thesis, TNAU, Coimbatore. 